\title{
Discurso ecológico, polarização ideológica e estetização do político: a (contra) visualidade no documentário Belo Monte - Anúncio de uma Guerra (2012) de André D'Elia
}

\author{
Sebastian Thies \\ Suzana Vasconcelos de Melo
}

DOI - 10.25160/v5i2.d2

\section{Colonialismo, desenvolvimentismo e discurso da natureza}

A imagem da água na cultura ocidental está associada à vida, renovação, força e pureza, e, no caso do Brasil, de forma especial, à ideia de abundância, sendo a água, juntamente com as florestas, um dos principais componentes das imagens que representam o Brasil tanto no exterior quanto em solo nacional. Este fenômeno se manifesta tanto no discurso fundador, como no texto que deu origem ao discurso colonial no Brasil, o relato do descobrimento. A carta de Pero Vaz de Caminha de primeiro de maio de 1500 endereçada ao rei de Portugal dando notícias do descobrimento, que consistia num diário dos primeiros dias de estadia no novo continente, contém a palavra água mais de vinte vezes na descrição da nova terra, como na declaração de Caminha que se tornaria célebre: “Águas são muitas; infindas. E em tal maneira é graciosa [a terra] que, querendo-a aproveitar, dar-se-á nela tudo, por bem das águas que tem." ${ }^{1}$ Porém, para além do discurso teológico invocando a visão do paraíso presente tanto na carta do descobrimento quanto em tantos outros escritos do período colonial, sobressai-se uma percepção estética do meio ambiente e da natureza tendo também em vista sua exploração econômica. Carvalho aponta para a onipresença do discurso colonial da natureza em todos os gêneros literários no Brasil, e isto de tal forma, que a qualidade da descrição das paisagens naturais funcionava como critério de valor para os primeiros críticos literários ainda no século XIX (Carvalho, 2005: 21-33). Segundo a autora, o registro cronístico dos viajantes, que davam ênfase à descrição minuciosa das especificidades da natureza local a fim de que seu potencial econômico e de ocupação se fizesse claro aos olhos de seu soberano, influenciaria sobremaneira a forma como a natureza se manifesta até mesmo na poesia brasileira:

1 Ver Caminha, Pero Vaz de. A Carta, de Pero Vaz de http://www.dominiopublico.gov.br/download/texto/ua000283.pdf. Acesso em 12-10-2126.

ßRASILIANA- Journal for Brazilian Studies. Vol. 5, n.2 (July, 2017). ISSN 2245-4373. 
Do registro ao tratamento poético da natureza, houve um caminho que se foi traçando de acordo com o processo de identificação do colono, cronista ou poeta, com a terra e com a influência das correntes literárias.

Mas podemos dizer que, entre nós mais do que em qualquer outra literatura, preponderou a identificação entre a natureza e o país. Mesmo com a linguagem do registo tomada do cronista, o poeta opera essa identificação. Motivo de registro informativo ou panegírico, a natureza é tratada com a função de valorizar o Brasil, de despertar a atenção e de, num primeiro momento, atrair o interesse do futuro povoador ou da Metrópole. (Carvalho, id: 48-49)

Notadamente a natureza como símbolo de exaltação do país e da brasilidade é um dos elementos aglutinadores da imagem da identidade nacional, a qual se desenvolveria a partir do romantismo. Portanto, não obstante a aura de poeticidade e contemplação que envolvem o tratamento dado ao motivo da natureza pelo romantismo, o discurso político permanece latente, e entrelaçado ao estético. No século XX e na pós-modernidade nos deparamos com um cenário muito mais complexo envolvendo não apenas a imagem e o significado da natureza, mas também as mídias modernas. Ao longo do último século a imagem da abundância dos recursos naturais esteve tanto associada à ideia de riqueza material quanto de espelhamento da grandeza e brio da identidade do brasileiro, do mesmo modo como a ausência da abundância resulta numa imagem crítica da sociedade e no outro negativo da identidade nacional.

Como o berço econômico do Brasil reside na atividade agrária, cinco séculos depois da carta de Caminha, a água mantém a centralidade no debate eco político. Durante os anos 1930, a escassez de água se constituiu em símbolo do subdesenvolvimento da sociedade patriarcal no Nordeste brasileiro, tornando-se um emblema da denúncia social do modernismo regionalista através de obras canônicas tais como Vidas Secas de Graciliano Ramos e O Quinze de Raquel de Queiroz. Atualmente a escassez de água não atinge apenas as populações que habitam os recôncavos do Brasil, mas também os moradores das cidades grandes, a exemplo disto temos a recente "crise da água" na cidade de São Paulo, a mais grave em 80 anos. $^{2}$ Da mesma forma como a população dos grandes centros metropolitanos

\footnotetext{
${ }^{2}$ Ver Barifouse, Rafael. Maior crise hídrica de São Paulo expõe lentidão do governo e sistema frágil. In: $B B C$ Brasil, 22 de março de 2014. Disponível em: http://www.bbc.com/portuguese/noticias/2014/03/140321 seca saopaulo rb. Acesso em 12.10.2014.
}

ßRASILIANA- Journal for Brazilian Studies. Vol. 5, n.2 (July, 2017). ISSN 2245-4373. 
já está familiarizada com as imagens das secas, na mídia se propagam imagens de enchentes e alagamentos que denotam um excesso de água. Esses problemas, antes de serem decorrentes de fatores climáticos, caracterizam-se predominantemente pela má gestão dos recursos naturais no Brasil, pela ausência de planejamento social e econômico, e pela falta de leis ambientais rigorosas. Tais problemas espelham, ademais, uma relação cultural do brasileiro com o meio ambiente, povoada pelo mito da infinitude e da abundância dos recursos naturais que somente nas últimas décadas começou a ser revisada institucionalmente. ${ }^{3}$

Atualmente, no contexto da contenda ecológica no Brasil, tem um papel de destaque o megaprojeto de construção da usina hidrelétrica de Belo Monte no rio Xingu na região de Altamira no Estado do Pará, que foi anunciada pelo governo e pela imprensa como a terceira maior barragem do mundo. ${ }^{4}$ As obras de Belo Monte tiveram oficialmente início em 2011, porém o projeto de construção da usina se arrasta desde os anos setenta, como parte do plano de intervenção e exploração dos recursos naturais na área de selva amazônica, na época elaborado pelos governos militares e setores do capital.

No embate político, a visualização do projeto desempenha um papel fundamental e muito complexo. Nossa contribuição se debruçará sobre a análise do papel da estetização de espaços naturais e da construção de indigenidade no discurso ecológico no documentário Belo Monte - Anúncio de uma guerra (2012) de André D'Elia. O filme documenta o confronto entre os advogados do desenvolvimentismo estatal e os defensores dos setores atingidos pela construção da usina. Os discursos institucionais, a favor do complexo industrial se baseiam tanto na noção de abundância da água na região amazônica quanto em políticas de exploração que propõem aproveitar o potencial energético para atingir a demanda de

\footnotetext{
${ }^{3}$ A problemática pode ser notada nos investimentos dos governos brasileiros em inúmeras campanhas publicitárias na tentativa de conscientizar a população sobre o desperdício de água ao longo das últimas décadas. Segundo o sociólogo Eduardo Viola, um dos pioneiros na investigação sobre o movimento ecológico no Brasil, o pensamento ecológico começou a se difundir relativamente cedo no Brasil, ao mesmo tempo em que alcançou seu ápice nos países do $1^{\circ}$. mundo nos anos 1970, ganhando mais visibilidade após os anos 1980, após o fim da ditadura militar, quando figuras públicas da esquerda como Fernando Gabeira passaram a defender a causa ambiental. Os problemas ambientais da periferia em relação ao centro do capitalismo seriam similares no contexto da crise ecológica mundial, o que os diferenciaria é, no entanto, a desigualdade social da periferia e seus reflexos na relação dos indivíduos com o meio ambiente, o que muitas vezes reflete a forma predatória do capitalismo instaurado nestes países, acentua o pesquisador. Ver: Viola, Eduardo J. "O movimento ecológico no Brasil (1974-1986): do ambientalismo à ecopolítica". In: Revista brasisleira de Ciências Socias, v.1, n.3, São Paulo, fev. 1987.
}

${ }^{4}$ Ver dossiê especial online da Folha de São Paulo dedicado ao projeto: A Batalha de Belo Monte. In: Folha de S. Paulo, 2013. Disponível em: http://arte.folha.uol.com.br/especiais/2013/12/16/belo-monte/. Acesso em 25.07.2017. 
energia barata das indústrias brasileiras e das megacidades. Nota-se que o discurso hegemônico do desenvolvimentismo moderno exibe certos ideologemas residuais do colonialismo, visto que fundamenta parte de sua argumentação na ideia de aproveitamento da abundância dos aquíferos da Amazônia para alavancar o desenvolvimento econômico do país, sem levar em consideração o impacto de um projeto de tal porte na vida das populações ribeirinhas, dos indígenas, na flora e na fauna da região de selva amazônica no Pará.

Como Belo Monte até o momento das filmagens ainda estava em obras, o documentário de D'Elia gira em torno de uma catástrofe postergada para o futuro, tendo assim de lidar com a ausência de imagens contundentes que demonstrem o impacto social da obra a longo prazo. ${ }^{5}$ Este fato facilita ainda mais a finalidade do discurso institucional de tornar invisível os custos sociais e ambientais do projeto, constituindo-se através de uma lógica de disciplinamento do olhar - uma interpelação negativa que ordena: "move along, there's nothing to see here"(Rancière, 2010: 37). Esta atitude se confirma, por exemplo, no discurso oficial de Lula em 2010 a respeito da aprovação das obras da usina, ao chamar de "fantasias" os temores dos ambientalistas a respeito das consequências sociais e ambientais da obra:

É por essas fantasias construídas que a gente não tem que ter medo de debater. É por essas fantasias construídas que nós precisamos dizer: o estado do Pará e a região do Xingu não podem prescindir de Belo Monte, não tem como prescindir.

Meus companheiros, eu vou sair daqui e vou para Marabá. Vou anunciar o começo da terraplanagem da primeira siderúrgica do estado do Pará, para utilizar a energia produzida em Belo Monte. E em vez de exportar minério de ferro e comprar chips, a gente vai exportar produto com valor agregado para que essa meninada tão jovem possa trabalhar na siderúrgica e ganhar o pão de cada dia. ${ }^{6}$

\footnotetext{
${ }^{5}$ A usina foi inaugurada pela ex-presidente Dilma Rousseff em 05 de maio de 2016 e as consequências para a população e para o meio ambiente têm sido objeto de denúncia por parte de ONGs e também por parte da imprensa. Ver por exemplo reportagem em El Pais: Brum, Eliane. La historia de la familia de ribereños que, después de ser expulsada por Belo Monte, nunca consigue llegar. In: El Pais, 18 de julho de 2016 . Disponível em: http://internacional.elpais.com/internacional/2016/07/19/america/1468962598 126077.html. Acesso em 10.12.2016.

${ }^{6}$ Transcrição do discurso do ex-presidente Lula. Ver: Silva, Luiz Inácio da. Discurso do Presidente da República, Luiz Inácio Lula da Silva, no ato por Belo Monte e pelo desenvolvimento da região do Xingu-Altamira-PA (08min36s). In: Biblioteca da Presidência da República, 22 de junho de 2010. Disponível em:
} 
A citação de Lula não contém imagens que façam alusões à usina, pelo contrário, a usina se fragmenta em "ferro", "chips" e no sema "trabalho". As imagens sobre Belo Monte até o momento têm de operar de acordo a uma lógica visual do contrafatual. O discurso visual institucional não pode mostrar a usina em funcionamento porque as imagens da represa tão somente atestariam um fracasso institucional, que se reflete no fato do governo não ter podido impor sua ecopolítica e a usina se encontrar fechada por decisão judicial. Todavia, até certo ponto, o contradiscurso ecológico, tem que usar imagens genéricas (tomadas de outras catástrofes) para projetar a provável catástrofe sobre uma paisagem que ainda aparece intacta.

\section{Visualidade e contravisualidade segundo Nicholas Mirzoeff}

Para refletir sobre as práticas discursivas visuais presentes no documentário Belo Monte, anúncio de uma guerra (2012), recorremos à elaboração crítica de Mirzoeff sobre cultura visual em The Right to Look (2011) que aponta para a existência de uma cultura visual hegemônica e para a possibilidade de construção de uma contravisualidade como forma de oposição ao discurso hegemônico. O complexo da visualidade, segundo Mirzoeff, é uma forma hegemônica para disciplinar o olhar e evitar que o povo veja as consequências reais da ação política. Este complexo de poder visual se fundamenta em três aspectos: classificar, com a finalidade de impor à realidade um sistema de categorização; segregar ou destruir a existência política do polo subalterno; e finalmente, estetizar, com o intuito de naturalizar os efeitos do poder hegemônico:

A given modality of visuality is composed of a series of operations that can be summarized under three headings: first, it classifies by naming, categorizing, and defining - a process Foucault defined as "the nomination of the visible." (...) Next, visuality separates the groups so classified as a means of social organization. Such visuality segregated those it visualized to prevent them from cohering as political subjects, such as workers the people, or the (decolonized) nation. Finally, it makes this separated classification seem right and hence aesthetic. As Frantz Fanon had it, such

http://www.biblioteca.presidencia.gov.br/presidencia/ex-presidentes/luiz-inacio-lula-da-silva/audios/2010-audios$\underline{\text { lula/22-06-2010-discurso-do-presidente-da-republica-luiz-inacio-lula-da-silva-no-ato-por-belo-monte-e-pelo- }}$ desenvolvimento-da-regiao-do-xingu-altamira-pa-08min36s/view. Acesso em 12.10.2016.

ßRASILIANA- Journal for Brazilian Studies. Vol. 5, n.2 (July, 2017). ISSN 2245-4373. 
repeated experience generates an "aesthetic of respect for the status quo," the aesthetics of the proper, of duty, of what is felt to be right and hence pleasing, ultimately even beautiful. (Mirzoeff, 2011a: 476)

Segundo Mirzoeff, o domínio da visualidade primeiramente se expressa no contexto do cultivo da lavoura no regime escravocrata, começando pelo mapeamento cartográfico das plantações, porém estendendo-se pela divisão do trabalho dentro do modo de produção que criou um sistema de vigilância no qual a visão do senhor se segmenta, sendo transferida a seus subalternos. ${ }^{7}$ Isto posto para afirmar que visualidade - como forma de controle, mas também autoafirmação da visão a partir do poder - não se resume a elementos "visuais" em sentido estrito, nem deve ser compreendida numa relação meramente expressionista para com o sistema de dominação política: "Despite its name, this process is not composed simply of visual perceptions in the physical sense but is formed by a set of relations combining information, imagination, and insight into a rendition of physical and psychic space." (Mirzoeff, ibid: id). Como dado essencial para se compreender o modus operandi do complexo da visualidade, o autor se reporta ainda à técnica que se usava na estratégia militar para abarcar um campo de batalha que excedia o campo visual do observador individual no contexto da publicística da guerra a partir do século XVIII:

Visuality is an old word for an old project. It is not a trendy theory-word meaning the totality of all visual images and devices, but it is in fact an early nineteenth-century term, meaning the visualization of history. This practice must be imaginary, rather than perceptual, because what is being visualized is too substantial for any one person to see and is created from information, images, and ideas. (Mirzoeff, ibid: 478)

Visualizar uma obra faraônica, como é o caso da usina de Belo Monte a médio e longo prazo exige um poder de abstração e ficcionalização, o que representa um grande desafio a sua representação midiática, colocando em questão a narratibilidade da situação. Disto resulta, que na ausência das imagens que possam tornar palpáveis as dimensões apocalípticas do projeto, ambos os discursos recorrem às mesmas imagens da natureza, em sua grande maioria concentradas no motivo da floresta e da água. No caso desta última, o que muda é tão somente o conteúdo semântico, isto é, por um lado água denota fonte de vida, e por

\footnotetext{
${ }^{7}$ A respeito do processo de assimilação da consciência do opressor por parte do oprimido, consultar "Pele negra, máscaras brancas" de Fanon, uma obra que decididamente influência o pensamento crítico nos estudos pós-coloniais. Ver: Fanon, Frantz. Pele negra, máscaras brancas. Tradução de Renato da Silveira. EDUFBA, Salvador, 2008.
} 
outro fonte energética. Assim, é possível compreender o uso que se dá a imagem da água como símbolo coletivo 8 à medida que esta serve para reinserir o discurso especializado (do engenheiro, do ecologista, do antropólogo) na contenda política cotidiana, tornando visível uma crise que escapa ao poder de entendimento. Para opor-se ao efeito do disciplinamento do olhar presente nos discursos institucionais e no mainstream medial, o discurso ecológico tem que divisar uma contravisualidade que reclama o direito de olhar de uma minoria social apesar do disciplinamento (Mirzoeff, ibid: 477).

\section{Discurso ecológico e ativismo midiático em Belo Monte - Anúncio de uma guerra}

O título do documentário Belo Monte - Anúncio de Guerra se refere à polarização ideológica em torno da construção da usina, deixando claro seu posicionamento ideológico que prediz uma militarização do conflito. $\mathrm{O}$ título citando a guerra introduz ainda uma referência histórica que retoma o "Primeiro Encontro das Nações Indígenas do Xingu" em 1989, quando a ativista indígena "Tuíra" apontou seu facão para o rosto do então presidente da Eletronorte, José Muniz Lopes num gesto simbólico de resistência. Em razão da comoção que o ato de protesto dos Kaiapós gerou, o Banco Mundial chegou a retirar o financiamento para a construção da Usina, adiando a retomada do projeto. ${ }^{9}$

Portanto, é o desafio e o esforço de construção do contraolhar que nos interessa examinar no documentário de André D’Elia. A narrativa de D'Elia denuncia os impactos negativos do projeto e a falta de democracia na decisão de construção da usina, à revelia da comunidade indígena, para assim divulgar o problema internacionalmente com o intuito de angariar apoio para a causa dos Kaiapós. Desse modo, o filme se situa no polo oposto ao discurso nacionalista governamental que em sua pose pós-colonial veta qualquer intervenção internacional relativa ao desenvolvimento da Amazônia, em defesa de um suposto interesse nacional. Ao denunciar os interesses econômicos privados e estrangeiros por trás da posição do governo, D`Elia desmonta a base do discurso hegemônico e aposta na estratégia de uma transnacionalização da resistência ecológica, retomando, por exemplo,

\footnotetext{
${ }^{8}$ Sobre símbolo coletivo ver: Jäger, Siegfried. Kritische Diskursanalyse. Eine Einführung. Unrast, Münster, 2015. $7^{\circ}$. Ed. pp. $133-138$.

${ }^{9}$ Sobre o tema ver: Calvi, Miquéias Freitas (Coord.); Alves, Juliete Miranda; Nascimento, Huandria Figueiredo. Relatório Análitico. Atividades de Pesquisas - CAI Transamazônica. Serviço Público Federal, Universidade Federal do Pará, Campus Universitário de Altamira. Célula de Acompanhamento e Informação do Território da Cidadania da Transamazônica. Altamira, nov. /2011. Disponível em: http://sit.mda.gov.br/download/ra/ra095.pdf. Acesso em 13.10.2016.
} 
um ponto crucial do discurso ecológico da Amazônia como patrimônio da humanidade. Assim, o cineasta apela para a consciência ambiental de um público mundial, tendo, porém, que arcar com certa generalização do discurso documental e da estética midiática.

O filme de André D’Elia entende-se como ativismo midiático, no sentido de que aqui a mídia do documentário serve ao esclarecimento ecológico e conscientização, representando ao mesmo tempo parte da mobilização de uma contraesfera pública. Consequentemente, no filme se encontram passagens que apresentam um caráter expositivo e jornalístico entrelaçadas a um posicionamento político explícito do cineasta que não o impede de ironizar e parodiar os representantes da esfera do poder os quais defendem o projeto de construção da barragem. Em virtude dos recursos limitados para realização das filmagens, captados através de crowdfunding ${ }^{10}$, o filme de estreia de André D'Elia representa uma obra híbrida e imperfeita na acepção do "cine imperfecto" de García Espinosa. ${ }^{11}$ Em vista disso, o filme se mostra ainda mais expressivo para uma reflexão a respeito da problemática da visualização da crise ecológica no documentário. De maneira complexa, estratégias discursivas convencionais e formas de estetização do ecológico unem-se na narrativa com passagens performáticas e reflexivas que antes podem ser entendidas como uma contravisualidade.

Devido ao fato da ausência de imagens da catástrofe ecológica, o filme se constitui predominantemente de entrevistas com especialistas, sendo eles ambientalistas, ecologistas e gestores de projetos, assim como militantes e artistas locais, lideranças indígenas e setores da comunidade de pescadores do Pará. Contudo, para defender o discurso desenvolvimentista - teoricamente dentro do formato do jornalismo profissional, que prima pelo ideal de neutralidade investigativa - o filme entrevistou um político local, e fez uso de imagens antigas de políticos e funcionários da alta cúpula do Consórcio Norte Energia se pronunciando em defesa da construção da barragem em redes de televisão.

A estrutura da narrativa fílmica em Belo Monte - Anúncio de uma guerra se caracteriza por intercalar talking heads e imagens as quais desempenham diferentes funções

\footnotetext{
${ }^{10} \mathrm{O}$ documentário conseguiu uma arrecadação de 121 mil reais durante 15 dias no site de financiamento coletivo Cartase. Ver: Documentário aborda impacto da obra da usina de Belo Monte no Pará. In: Globo.com, 7 de dezembro de 2011. Disponível em: http://g1.globo.com/natureza/noticia/2011/12/documentario-aborda-impacto-da-obra-da-usina-de-belomonte-no-para.html. Acesso em 25.07.2017.

${ }^{11}$ Ver Espinosa, Julio García. Por un cine imperfecto. Castellote Ed., Madrid, 1976.
} 
compensatórias em relação ao grau de abstração do conteúdo veiculado nas entrevistas, sendo empregadas para:

a) Inserir a opinião dos experts entrevistados na realidade socioambiental do Pará: imagens anônimas de florestas, rios, e catástrofes ecológicas são intercaladas aos depoimentos de ambientalistas, cineastas, autoridades e outros entrevistados enquanto estes tentam explicar a situação para o público;

b) Deslegitimar o ponto de vista dos oponentes, isto é, dos favoráveis à construção da usina, através de uma representação caricaturesca dos mesmos: este fato é evidente na montagem ideológica de declarações de políticos amazonenses em defesa da obra logo após a afirmação do líder indígena de que os políticos sempre mentem. Para tornar mais explícito ainda para o expectador que o depoimento do político exibido não deve ser levado em consideração, o filme exibe um cartaz com a imagem do político nas ruas da sua época de campanha eleitoral. Evidentemente é uma manobra discursiva para angariar a simpatia do público brasileiro ressabiado com escândalos de corrupção no país e decepcionado com os políticos;

c) Explicar: no intuito de traçar uma cartografia da catástrofe e tornar visível a tragédia anunciada, o documentário recorre a mapas animados da bacia hidrográfica nos quais se ilustra para o público o que pode acontecer com o ecossistema, caso não apenas esta usina, mas outras venham a ser construídas na região de selva;

d) Corrigir a ausência de outras imagens: isso se dá através da utilização de imagens genéricas, fora de contexto, que têm um efeito de sinédoque da destruição, como as escavadeiras em um barranco ou a explosão no meio da floresta, que fazem uma alusão abstrata à obra em andamento;

e) E por fim, para a construção do locus amoenus, o qual analisaremos mais detidamente, por se tratar de um elemento que desempenha um papel central no diálogo que o documentário tenta estabelecer com o expectador e no apelo à sua comoção.

\section{A espetacularização do outro na narrativa e a construção do locus amoenus}

Em primeiro lugar, a representação do locus amoenus se dá através das primeiras imagens do filme, tendo uma floresta à margem de um rio como pano de fundo que simboliza a natureza intocada pelo ser humano, acompanhada do som da floresta, e de elementos que remetem a um discurso étnico, tais como o som de instrumentos de percussões e cantos

BRASILIANA- Journal for Brazilian Studies. Vol. 5, n.2 (July, 2017). ISSN 2245-4373. 
indígenas. Por um lado, esta imagem representa um topos que remonta ao romantismo e à consciência nostálgica presentes nas origens do discurso ecológico durante os anos 1960, servindo para ativar no expectador seu repertório cultural do significado da natureza. Por outro lado, esta imagem se revela ambígua, assim como as posteriores imagens de água e máquinas às quais o filme recorrerá ao longo da narrativa, pois se tratam de elementos que também compõem o repertório estético da visualidade do discurso hegemônico, caracterizado por excluir, e/ou transfigurar o outro.

A estratégia de construção do locus amoenus no filme se dá, em segundo lugar, através do contraste da paisagem natural com uma paisagem urbana marcada pela velocidade e pela alienação, o que pode ser visto nas imagens em câmera acelerada do trânsito, e também se depreende do ritmo da música de fundo. Formando este cenário são postas em cena imagens de um céu cinza, de luzes artificias, que neste contexto obviamente fazem uma referência à demanda de enérgia elétrica da cidade grande. Compondo este cenário sombrio, a narrativa recorre a uma encenação explícita do estresse e nervosismo do sujeito urbano, como podemos ver numa cena protagonizada pelo próprio diretor do filme que se deixa. Verifica-se no início da cena que ainda é dia, e que o escurecer se dá através da utilização de um filtro cinza, de modo que estas imagens alteradas, que têm um efeito de desfamiliarização (Verfremdungseffekt) em sentido brechtiano, fazem alusão ao mitema do crepúsculo do homem moderno. A paisagem urbana se contrapõe diretamente à cena seguinte do filme, que tem como motivo um pôr do sol alaranjado e brilhante se refletindo nas águas cristalinas de um rio, com imagens de índios se banhando. Claramente com o intuito de interpelar ideologicamente (em sentido althussiano) um público citadino, o filme apela para imagens turistificadas tanto da representação da natureza quanto do índio como parte dela, incorrendo no discurso da "nostalgia imperialista", termo cunhado pelo antropólogo Renato Rosaldo ao se referir à imagem que os antropólogos constroem dos povos indígenas:

Imperialist nostalgia revolves around a paradox: A person kills somebody, and then mourns the victim. In more attenuated form, someone deliberately alters a form of live, and then regrets that things have not remained as they were prior to the intervention. At one more remove, people destroy their environment, and then they worship nature. In any of its versions, imperialist nostalgia uses a pose of "innocent yearning" both to capture 
people's imaginations and to conceal its complicity with often brutal domination. (Rosaldo, 1989: 69-70)

O terceiro aspecto aqui observado da construção do locus amoenus diz respeito à mitização da trajetória da equipe de filmagem da cidade até à aldeia indígena. Através do registro fragmentado e apurado da viagem da equipe de filmagem, com imagens dos diferentes meios de transportes utilizados para se chegar à floresta (o avião, o jeep e o barco), o cineasta reflete, por um lado, sobre a presença do observador na paisagem natural, e por outro lado, com a utilização de clichês que povoam o imaginário moderno se adapta a uma linguagem cinematográfica de interpelação da massa, convidando o expectador a participar de uma aventura pela selva. Nas cenas da viagem de barco, o observador se encontra personificado na figura do barqueiro com cabelos esvoançando ao vento - a ironia é que o barqueiro é um indígena - uma metáfora para a intepridez do navegante rumo ao desconhecido que claramente representa um eco do interdiscurso da colonização, "os dizeres firmados em outro lugar, mas que são retomados para sustentar os discursos contemporâneos" (Miranda, 2008: 37). Esta reconstrução da viagem pode ser compreendida como reencenação do mito do achamento, como registro da chegada da civilização moderna à natureza selvagem.

É possível observar ainda que a representação da natureza é constantemente marcada pela presença do homem ou das máquinas, nunca em seu estado puro, o que demonstra uma integração de fragmentos do discurso do desenvolvimentismo moderno ao discurso ecológico. ${ }^{12}$ Isto se torna patente em uma imagem ambivalente dos barcos e cargueiros no rio ilustrando o depoimento de uma ativista que reclama do fato da construção da usina destruir um rio que até então era navegável.

Também a incomensurabilidade e inenarrabilidade do ecossistema é tematizada através da adoção de uma linguagem cinematográfica grotesca e autoirônico que atesta o fracasso dos recursos cinematográficos. A natureza aparece com frequência como pano de fundo dos depoimentos dos entrevistados, a exemplo do que ocorre nas primeiras cenas do documentário, que exibem a palestra do cacique Raoni na França tendo uma parede às suas costas com fotos de indígenas devidamente caracterizados e gravuras de espaços naturais. Sendo assim, de diversas maneiras, na ausência da natureza em torno da qual os

\footnotetext{
${ }^{12}$ Sobre o desenvolvimento do movimento ecológico, segmentação, relação com o Estado e ideologias ver: Viola, Eduardo J. Opus cit.
} 
depoimentos se concentram, a narrativa cinematográfica se mostra todo o tempo consciente da necessidade de presentificá-la em imagens familiares ao sujeito urbano.

No documentário, o indígena faz parte da composição do locus amoenus, sendo representado de forma folclórica. Este fato constitui um problema a ser explorado na narrativa de D'Elia quando afirmamos que este, apesar de demonstrar uma posição crítica em relação à construção da usina e em favor das "minorias", oferece ao expectador um retrato comodificado da alteridade, que em nada se diferencia da visão dominante, do "espetáculo das raças", que se perpetua na sociedade brasileira desde a colonização sob variantes diversas. ${ }^{13}$

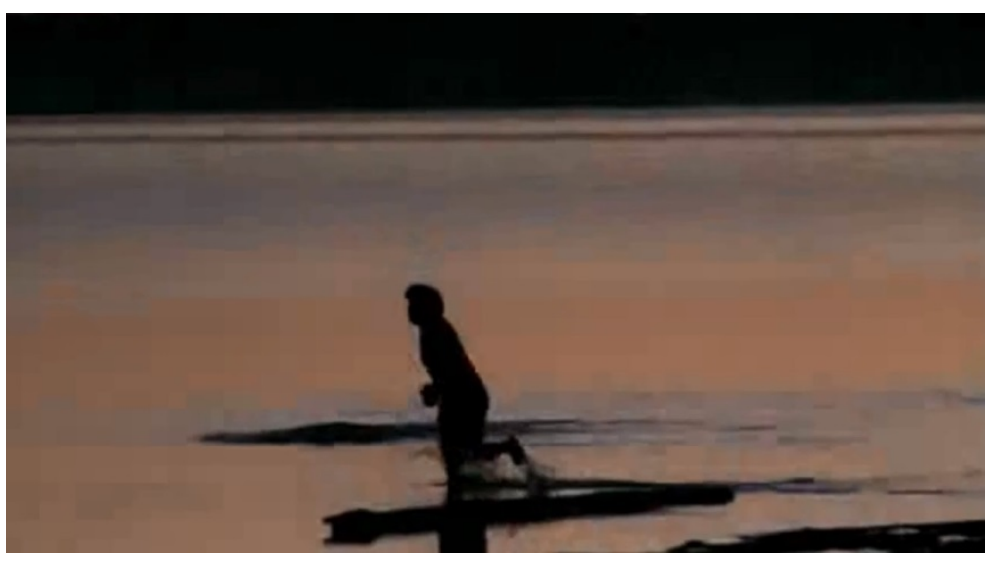

Figura 1 - Indígena e locus amoenus em Belo Monte- Anúncio de uma Guerra

As imagens apresentando os indígenas lançam mão de uma estética do olhar turistificado, que não reconhece no índio um sujeito, mas sim um mero componente da paisagem natural, um elemento central do discurso do colonizador incapaz de lidar com a alteridade. ${ }^{14}$ Como componentes deste imaginário popular sobre o indígena no Brasil, resultante de políticas culturais de identidade racial marcadas por um olhar etnocêntrico, no filme se destaca a representação do corpo romantizado do índio, uma representação da cultura indígena congelada no tempo, mística, ingênua, atrasada, e, portanto, incapaz de elaborar uma resposta racional para os seus próprios problemas como fazem os indivíduos modernos. $\mathrm{O}$

\footnotetext{
${ }^{13}$ Sobre a forma como a questão racial foi tratada pelas políticas identitárias nas instâncias do poder no Brasil ao longo da história ver: Schwarcz, Lilia. O espetáculo das raças. Companhia das Letras, São Paulo, 1993.

${ }^{14}$ Em um capítulo de Dialética da colonização, Bosi faz uma análise da poesia de Anchieta através do que este demonstra como o processo de aculturação promovido pelos jesuítas operava pela linguagem, criando um interespaço no qual os indígenas vão perdendo as opções simbólicas de autoexpressão, tendo que falar sobre a própria cultura na língua do dominador: "O projeto de transpor para a fala do índio a mensagem católica demandava um esforço de penetrar no imaginário do outro, e este foi o empenho do primeiro apóstolo.” (Bosi, 2013: 65)
} 
expectador é confortado com imagens de indígenas preparando seus alimentos com ingredientes da culinária tradicional, além de seus hábitos "primitivos", como comer no chão de cócoras e com as mãos, e habitar e em cabanas rudimentares - vale destacar que estas últimas compõem uma parte importante da mise-en-scène.

Esta visão do índio como um artefato do passado, que reflete um "olhar taxidermista" - como afirma a antropóloga visual Fatimah Tobing Rony (2001:14) - é muito difundida na sociedade brasileira, - sendo transmitida de geração para geração nas escolas pelos livros didáticos, um dos principais instrumentos de sistematização e legitimação do olhar hegemônico, alimentando assim o imaginário popular.

Outrossim, há que se mencionar que a auto encenação dos indígenas diante das câmeras pode ser compreendida como um reflexo da submissão às políticas de identidades culturais disseminadas pelo complexo midiático, que são frequentemente impostas de forma renovada aos grupos indígenas por parte de seus defensores, como ONGS e outras organizações, conforme denuncia Conklin em sua análise sobre a centralidade do corpo exótico para a aceitação de autenticidade cultural por parte do público ocidental:

The ways in which indigenous authenticity is communicated to the supporters of advocacy organizations constitute another concern. NGOs rely heavily on motivating donors to make voluntary contributions, and photographs, slides, and video are important fund-raising tools. Advocates who hope to evoke interest and sympathy for indigenous peoples often consciously recognize the potency of exotic visual images as symbolic communicators of authenticity. (Conklin, 1997: 722)

\section{A militarização do discurso ecológico como estratégia de sensibilização}

A principal estratégia narrativa de D'Elia para alcançar uma interpelação ideológica por meio da comoção do expectador não está fundamentada no discurso ecológico propriamente dito, mas no imaginário da violência. Segundo a narrativa, a possibilidade de destruição do meio ambiente com a construção da usina seria responsável por destruir a paz na região de Altamira no Pará, predizendo um derramamento de sangue. Mais uma vez trata-se de uma estratégia para compensar a ausência de imagens que deem conta da catástrofe ecológica com a intenção de chegar a uma radicalização do discurso documental dentro do paradigma da contravisualidade. 
Segundo o filme, a guerra será uma consequência tanto do enfrentamento entre as forças de opressão do Estado e os indígenas e ativistas políticos, quanto dos problemas sociais que seriam agravados com a construção da usina, ao invés de amenizados como prevê o acordo entre governo e construtora. Os entrevistados preveem um aumento da criminalidade em virtude de um previsto vertiginoso crescimento populacional na região de Altamira a qual não dispõe de infraestrutura adequada para acomodar os supostos recém-chegados, provavelmente os operários da obra e pessoas atraídas por promessas de trabalho no município.

A militarização do discurso é um recurso empregado em larga escala em textos jornalísticos da grande imprensa no Brasil, em especial nos telejornais policialescos apresentados em rede nacional na tv aberta que obtém picos de audiência no final das tardes no país, tais como Cidade Alerta da Rede Record e Brasil Urgente da TV Bandeirantes, somente para citar dois que pertencem a uma tradição vasta do gênero, muito popular no país desde os anos $1990 .{ }^{15}$

Através da recorrência a metáforas de impacto chama-se a atenção do público, em especial de uma audiência urbana, para quem a imagem da guerra e das batalhas fazem parte de seu cotidiano cercado da violência urbana e seus mitos difundidos pelo sensacionalismo midiático. Em diversos momentos o filme recorre a esta estética do espetáculo, o que o torna não apenas o anúncio de uma catástrofe, mas também de uma guerra. Um exemplo disso são os videoclipes com imagens de trabalhadores da região em greve e das manifestações populares com performances da guerra na cidade, tendo como fundo musical um punk rock para reforçar a ideia de enfrentamento com o capital e com o Estado, representados por imagens do batalhão de choque intercaladas com filmes em preto e branco de soldados em formação no quartel. Por fim, para simbolizar o derramamento de sangue anunciado, o cineasta trata imagens de jornais locais, que reportam crimes cometidos na região, com um filtro vermelho.

Deve-se mencionar, que o mote para o discurso combativo no documentário de D'Elia - e portanto, um componente do discurso da contravisualidade - foi inspirado na declaração de guerra ao homem branco, como representante do colonizador e do capitalista moderno, dos Kaiapós e do movimento ecológico nos anos 1980, uma estratégia política

\footnotetext{
${ }^{15}$ Sobre o tema, ver: Barbosa, Bia. Programas policialescos: a legitimação da barbárie. In: Carta Capital, 10 de julho de 2015. Disponível em: http://www.cartacapital.com.br/blogs/intervozes/programas-policialescos-a-legitimacao-dabarbarie-1735.html. Acesso em 12.10.2106.
}

ßRASILIANA- Journal for Brazilian Studies. Vol. 5, n.2 (July, 2017). ISSN 2245-4373. 
impactante por sua radicalidade para além do discurso reformista, que concomitantemente tenta resgatar o orgulho identitário indígena como povo guerreiro. Entretanto, a ressignificação do contradiscurso combativo dos indígenas no contexto sócio-político e midiático dos anos 2000, revela sua obsolescência e ineficácia como fator de pressão política, compondo um discurso que se deixa não apenas facilmente cooptar, mas dissolver-se em meio a atmosfera de simulacro criada pelo sensacionalismo midiático. No filme de D’Elia, um comentário involuntário, mas bastante acertado, que faz alusão à comodificação do índio, chama a atenção do expectador atento na entrevista com o bispo Dom Erwin quando este cita que o facão da líder indígena Tuíra teria se tornado a "logomarca" do movimento contra Belo Monte: „Essa foto que virou quase que a logomarca na luta contra Karara”.

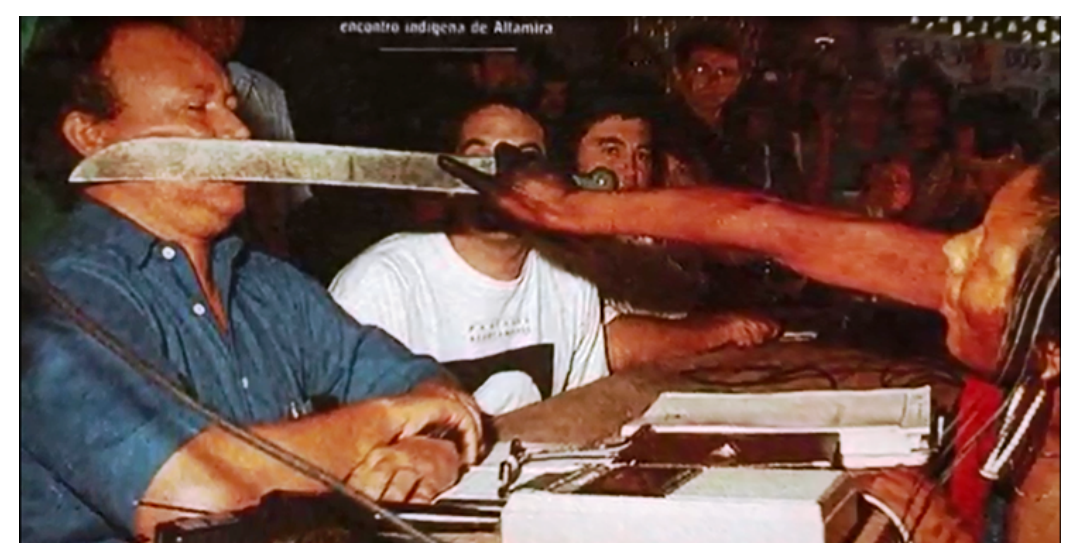

Figura 2 - Imagem de 1989 com gesto simbólico da ativista indígena Tuira em Belo Monte-Anúncio de uma Guerra

\section{Rumo a uma estética da contravisualidade: a autoreflexividade da narrativa e o compromisso com os movimentos sociais}

Uma forma de compensar a utilização de imagens ambíguas e fragmentos do discurso hegemônico que o filme escolheu foi construir um metadiscurso autoreflexivo e performático. A narrativa mostra-se consciente da problemática envolvendo o uso de imagens na representação do outro e das implicações de tal procedimento. Visto que opta por um discurso ecológico politizado, a estética convencional do filme de D’Elia parece se pautar na máxima segundo a qual os fins justificam os meios, porém apresenta uma reflexão sobre o papel negativo da mídia nas contendas indígenas. Sendo assim lança mão de imagens que remontam à época da ditadura militar e exibe um vasti material tomado de reportagens históricas e programas de televisão sobre a temática no intuito de dar conta da 
dimensão histórica do conflito em torno da ocupação e posse da região amazônica. Com isso, D'Elia coloca em questão o papel que a grande imprensa desempenha neste contexto, e denuncia sua omissão diante das questões sociais à medida que emprestam seu aparato aos representantes das grandes corporações, dos agentes do Estado e aos políticos desacreditados de antemão por uma grande parcela da sociedade brasileira.

Ao expor o suporte tecnológico da mídia o filme estabelece um distanciamento irônico (do tipo brechtiano), inclusive através da exibição de tecnologia anacrônica, como por exemplo, imagens em preto e branco que remontam à ditadura militar num aparelho de tv muito antigo que pode causar um estranhamento ou suscitar pelo menos uma indagação por parte do público. Sua crítica se dirige preponderantemente à televisão brasileira que se manifesta claramente não apenas na exibição das reportagens televisivas, mas na filmagem de diversos televisores. Essa imagem mostra o framing $^{16}$ da informação, uma declaração de que a televisão é a moldura da informação tendenciosa e hegemônica a qual a grande maioria dos telespectadores brasileiros tem acesso, majoritariamente como única fonte de informação. Nas cenas finais do documentário a câmera mostra o exato momento no qual um aparelho de televisão é desligado, para em seguida mostrar um completo apagão na cidade. Isto tudo tendo como soundtrack um rap de "Gabriel - o Pensador" no qual o compositor assevera:" A programação existe pra manter você na frente, na frente da TV, que é pra te entreter, que é pra você não ver que o programado é você."

A autoreflexividade também se faz presente no início do filme, no momento em que a equipe de filmagem se coloca como representante do homem branco e da cultura urbana. As cenas do trajeto demonstram o movimento da cidade indo de encontro a floresta. Outrossim, conforme já dito, o filme tenta adquirir legitimação ao se posicionar como mídia alternativa, mantendo um posicionamento ideológico claro ao reclamar para si uma posição próxima à visão dos indígenas que chegam a declarar para o cineasta que os brancos mentem, inclusive os jornalistas. Por esta razão, a narrativa é enfática em relação as atribuições da mídia como aliada dos políticos e das grandes empresas. Este efeito é alcançado através da exibição de entrevistas de políticos e empresários em programas de TV defendendo Belo Monte.

Porém o documentário também não deixa de reconhecer o papel positivo da mídia para o movimento ambientalista através das cenas das visitas de Sting e James Cameron à

\footnotetext{
${ }^{16}$ Sobre o conceito de framing ver: Benford, Robert; Snow, D. David A. Framing Processes and Social Movements: An Overview and Assessment. In: Annual Review of Sociology, V. 26, 2000, pp. 611-639.
}

ßRASILIANA- Journal for Brazilian Studies. Vol. 5, n.2 (July, 2017). ISSN 2245-4373. 
Amazônia. Concomitantemente, deixa entrever uma reflexão sobre o desgaste do discurso ecológico, que precisaria recorrer a novas estratégias discursivas, o que o trabalho de D’Elia, no entanto, não faz quando tenta retomar uma tática de mobilização utilizada nos anos 1980 por parte dos ecologistas para intimidar setores do capital internacional como o encontro em Altamira em 1989, marco do movimento socioambiental, com a presença da imprensa nacional e internacional, inclusive o já citado cantor Sting, cujas imagens percorreram o mundo, onde também foi feita a já citada foto da líder indígena com o facão. ${ }^{17}$

É possível afirmar que a maneira encontrada pelo documentário para se posicionar diante do mainstream visual está representada na sequência de imagens aceleradas e desconexas das manifestações dos momentos sociais na cidade grande, destacando o caráter perfomático dos manifestantes organizados, que apresentam uma nova forma de tornar visível a guerra através da carnavalização e da performance. Trata-se de mais uma tentativa do cineasta de abarcar a dimensão terrificante que a construção da usina prediz. O filme chega a apresentar a denúncia de que por trás da construção da usina há interesses tais, como transformar a área e os rios em territórios de mineração, o que pode significar a morte da floresta a longo prazo. Para finalizar, o documentário de D’Élia se reporta às imagens da morte e da guerra performada nas ruas, retornando desta maneira a cidade, o que dá uma circularidade a narrativa, reforçando a mensagem do documentário de que a Amazônia é responsabilidade de todos e de a cidade possui uma relação de dependência com a natureza. A ação da resistência presente nas manifestações representa um desafio para o discurso da visualidade, que de acordo com Mirzoeff, é sempre imperialista (Mirzoeff, 2011b: 196). Na ausência de imagens contundentes da catástrofe, o cineasta capta momentos nos quais os movimentos sociais ocupam o espaço público e reclamam para si um lugar que não pode ser de todo controlado pela visualidade hegemônica, produzindo assim imagens fora de controle, por exemplo, a imagem dos seguranças da Elotronorte que reagem à interpelação da imprensa e manifestantes de forma agressiva e obscena.

17 O histórico de Belo Monte está disponível no site antigo do Instituto Socioambiental: https://siteantigo.socioambiental.org/esp/bm/hist.asp. Acesso em 10.12.2016.

ßRASILIANA- Journal for Brazilian Studies. Vol. 5, n.2 (July, 2017). ISSN 2245-4373. 


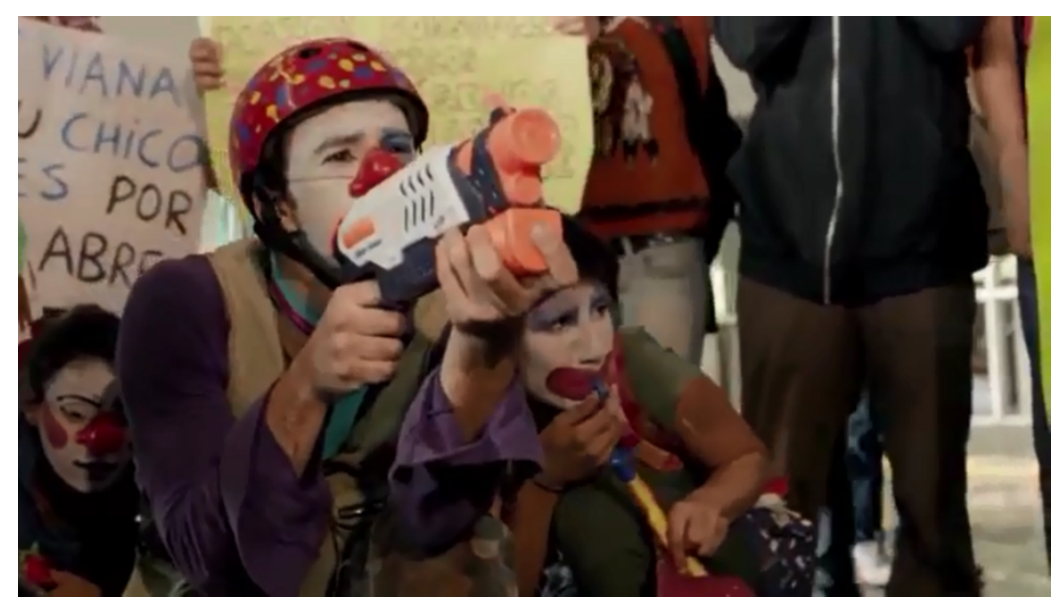

Figura 3 - Imagem de uma manifestação em Belo Monte- Anúncio de uma Guerra

O filme se encerra com um posfácio composto por uma sequência de cenas que registra o momento no qual os entrevistados se calaram diante da câmera de D’Elia. O silêncio coletivo expressa a impotência e capitulação dos indivíduos diante da atrocidade que mais uma barragem representa para o meio ambiente, chama a atenção para os limites da narratibilidade da situação, bem como acentua o esforço do cineasta para esgotar as possibilidades de representação do problema, e por fim, o silêncio é a recusa digna, uma forma de resistência contra a visualidade.

\section{Conclusão}

À guisa de conclusão, vale salientar quão problemático se mostra para o ativismo midiático ao estilo de D'Elia o intento de construir uma contravisualidade efetiva, visto que o contradiscurso tem de recorrer ao arsenal visual acumulado sob o domínio da visualidade hegemônica. O problema com o qual o cineasta tem de lidar consiste em criar uma contraesfera pública num campo minado pelo discurso hegemônico e pela polarização política, e ao mesmo tempo escapar à armadilha da visualidade hegemônica. $\mathrm{O}$ financiamento coletivo e a distribuição do filme pela internet certamente trazem consigo uma indepedência que permite a veiculação de um conteúdo político incômodo. No entanto, aqui fica claro como recursos limitados, associados à necessidade de dar vazão a conteúdos locais para a comoção de um público global, geram uma economia do discurso que contraria o posicionamento radical da narrativa, fazendo com que o discurso ecológico no filme seja marcado pela contradição. A maior parte da informação sobre a catástrofe ecológica fica ao 
encargo de especialistas. As estratégias da visualização têm em vista uma carga afetivoemocional, pautando-se na espetacularização do outro como vítima da catástrofe ambiental e na militarização do discurso ecológico. As passagens autoirônicas e perfomáticas que refletem sobre a práxis fílmica e jornalística, postas em cena como parte do ativismo ecológico, aproximam-se de estratégias da contravisualidade, contudo, não fazem frente à espetacularização do discurso. Assim, também o silêncio nas cenas finais, como gesto simbólico da impotência do discurso, acaba por diluir-se em páthos.

\section{Bibliografia}

A Batalha de Belo Monte. In: Folha de S. Paulo, 2013. Disponível em: http://arte.folha.uol.com.br/especiais/2013/12/16/belo-monte/. Acesso em 25.07.2017.

Barbosa, Bia. Programas policialescos: a legitimação da barbárie. In: Carta Capital, 10 de julho de 2015. Disponível em: http://www.cartacapital.com.br/blogs/intervozes/programaspolicialescos-a-legitimacao-da-barbarie-1735.html. Acesso em 12.10.2106.

Barifouse, Rafael. Maior crise hídrica de São Paulo expõe lentidão do governo e sistema frágil. In: $B B C$ Brasil, 22 de março de 2014. Disponível em: http://www.bbc.com/portuguese/noticias/2014/03/140321_seca_saopaulo_rb. Acesso em $\underline{12.10 .2014}$.

Benford, Robert; Snow, D. David A. Framing Processes and Social Movements: An Overview and Assessment. In: Annual Review of Sociology, V. 26, 2000, pp. 611-639.

Bosi, Alfredo. Dialética da colonização. Companhia das Letras, São Paulo, 2013. 4a․ Ed.

Brum, Eliane. La historia de la familia de ribereños que, después de ser expulsada por Belo Monte, nunca consigue llegar. In: El Pais, 18 de julho de 2016. Disponível em: http://internacional.elpais.com/internacional/2016/07/19/america/1468962598_126077.html. Acesso em 10.12.2016.

Calvi, Miquéias Freitas (Coord.); Alves, Juliete Miranda; Nascimento, Huandria Figueiredo. Relatório Analítico. Atividades de Pesquisas - CAI Transamazônica. Serviço Público Federal, Universidade Federal do Pará, Campus Universitário de Altamira. Célula de Acompanhamento e Informação do Território da Cidadania da Transamazônica. Altamira,

ßRASILIANA- Journal for Brazilian Studies. Vol. 5, n.2 (July, 2017). ISSN 2245-4373. 
Thies, Sabastian; Melo, Suzana. Discurso ecológico, polarização ideológica e estetização do político: a (contra) visualidade no documentário Belo Monte - Anúncio de uma Guerra (2012) de André D’Elia.

nov. /2011. Disponível em: http://sit.mda.gov.br/download/ra/ra095.pdf. Acesso em 13.10.2016.

Caminha, Pero Vaz de. A Carta, de Pero Vaz de Caminha. Disponível em: http://www.dominiopublico.gov.br/download/texto/ua000283.pdf. Acesso em 12.10.2016.

Carvalho, Paula Flávia. A natureza na literatura brasileira: regionalismo pré-modernista. Editora Hucitec, São Paulo, 2005.

Conklin, Beth A. body paint, feathers, and vcrs: aesthetics and authenticity in Amazonian activism. In: American Ethnologist, V. 24, No. 4, American Anthropological Association, 1997, pp. 711-732.

Espinosa, Julio García. Por un cine imperfecto. Castellote Ed., Madrid, 1976.

Documentário aborda impacto da obra da usina de Belo Monte no Pará. In: Globo.com, 7 de dezembro de 2011. Disponível em: http://g1.globo.com/natureza/noticia/2011/12/documentario-aborda-impacto-da-obra-dausina-de-belo-monte-no-para.html. Acesso em 25.07.2017.

Fanon, Frantz. Pele negra, máscaras brancas. Tradução de Renato da Silveira. EDUFBA, Salvador, 2008.

Jäger, Siegfried. Kritische Diskursanalyse. Eine Einführung. Unrast, Münster, 2015. 7ํ. Ed.

Miranda, Cristiane de Oliveira. Uma leitura discursiva do falar sobre o índio mídia impressa contemporânea de Mato Grosso. Cuiabá, 2008. Dissertação de Mestrado em Estudos da Linguagem na Universidade Federal de Mato Grosso.

Mirzoeff, Nicholas. The Right to Look. In: Critical Inquiry, Vol. 37, No. 3 (Spring 2011a), The University of Chicago Press, pp. 473-496.

The Right to Look. A Counterhistory of Visuality. USA, Duke University Press, 2011b.

Rancière, Jacques. Ten Theses on Politics. In: Dissensus on politics and aesthetics. London, New York, Continuum, 2010. pp. 27-44.

Rony, Fatimah Tobing. The Third Eye. Race, Cinema and Ethnographic Spectacle. Duke UP, Durham, 1996.

ßRASILIANA- Journal for Brazilian Studies. Vol. 5, n.2 (July, 2017). ISSN 2245-4373. 
Rosaldo, Renato. Imperialist Nostalgia. In: Representations No. 26, Special Issue: Memory and Counter-Memory (Spring, 1989), pp. 69-70.

Schwarcz, Lilia. O espetáculo das raças. Companhia das Letras, São Paulo, 1993.

Silva, Luiz Inácio da. Discurso do Presidente da República, Luiz Inácio Lula da Silva, no ato por Belo Monte e pelo desenvolvimento da região do Xingu-Altamira-PA (08min36s). Biblioteca da Presidência da República. Disponível em: http://www.biblioteca.presidencia.gov.br/presidencia/ex-presidentes/luiz-inacio-lula-dasilva/audios/2010-audios-lula/22-06-2010-discurso-do-presidente-da-republica-luiz-inaciolula-da-silva-no-ato-por-belo-monte-e-pelo-desenvolvimento-da-regiao-do-xingualtamira-pa-08min36s/view. Acesso em 12.10.2016.

Viola, Eduardo J. O movimento ecológico no Brasil (1974-1986): do ambientalismo à ecopolítica. In: Revista Brasileira de Ciências Sociais, v.1, n.3, São Paulo, fev. 1987. 